\title{
9366
}

\section{Inspiratory muscle effort, perfusion and oxygenation responses to inspiratory muscle training (IMT) with Tapered Flow Resistive Loading (TFRL) and Normocapnic Hyperpnea (NH) in COPD.}

COPD, Respiratory muscle, Exercise

\section{Z. Louvaris1, S. Dacha1, L. Janssens2, R. Gosselink1, I. Vogiatzis3, D. Langer1}

${ }^{1}$ Faculty of Kinesiology and Rehabilitation Sciences, Department of Rehabilitation Sciences, Research Group for Rehabilitation in Internal Disorders, KU Leuven. Respiratory Rehabilitation and Respiratory Division, University Hospital Leuven, Belgium. - LEUVEN (Belgium),

${ }^{2}$ Department of Rehabilitation Sciences, Musculoskeletal Research Group KU Leuven, Belgium. - LEUVEN (Belgium),

${ }^{3}$ Department of Sport, Exercise and Rehabilitation, Faculty of Health and Life Sciences, Northumbria University Newcastle, UK. - NEWCASTLE (United Kingdom)

Background: Inspiratory muscles of COPD patients undergo adaptations in response to stimuli of overload during IMT however little is known about specific characteristics of stimuli provided by different types of IMT.

Aim: To compare physiological responses of scalene [SCAL] and intercostal [INTER] muscles between two types of IMT.

Methods: In 7 COPD patients (FEV1:62 $\pm 15 \%$ pred) we measured cardiac output [CO] (impedance cardiography), $\mathrm{O} 2$ uptake, $\mathrm{O} 2$ delivery (by pulse oximetry \& $\mathrm{CO}$ ), pressure time product [PTPinsp] and total work of inspiration [Winsp] (esophageal catheter), SCAL and INTER muscles blood flow index [BFI] (NIRSICG) and oxygenation [\%StiO2] during a high intensity TFRL session of 30 breaths (50\%Pimax) and a $\mathrm{NH}(80 \% \mathrm{MVV})$ to exhaustion.

Results: Compared with TFRL, NH induced a greater increase in $\mathrm{CO}(6.4 \pm 0.5$ vs $5.9 \pm 0.5 \mathrm{~L} / \mathrm{min}), \quad \mathrm{O} 2$ uptake $(588 \pm 55$ vs $521 \pm 84 \mathrm{ml} / \mathrm{min}), \quad$ O2 delivery $(1.24 \pm 0.14$ vs $1.11 \pm 0.11 \mathrm{~L} / \mathrm{min})$ and PTPinsp $(-208 \pm 31 \mathrm{vs}-61 \pm 11 \mathrm{cmH} 2 \mathrm{O} / \mathrm{s} / \mathrm{min}, \mathrm{p}<0.05)$. However, SCAL and INTER muscles perfusion was lower during TFRL $(4.5 \pm 0.9 \& 1.7 \pm 0.3 \mathrm{nM} / \mathrm{s})$ as compared to $\mathrm{NH}(7.8 \pm 2.0 \& 2.6 \pm 0.4 \mathrm{nM} / \mathrm{s})$ that was accompanied by reduction in $\% \mathrm{StiO} 2$ (TFRL= SCAL:4.7 \pm 1.1 \& INTER:- $2.1 \pm 0.9$ vs $\mathrm{NH}=\mathrm{SCAL}: 0.8 \pm 1.5$ \& INTER:2.0 $\pm 0.5, p<0.05)$. Winsp was greater during TFRL $\left(1280 \pm 148\right.$ vs $\left.414 \pm 34 \mathrm{~L} / \mathrm{cmH}_{2} \mathrm{O}, p<0.05\right)$ and was negatively correlated with SCAL $(r=-0.65, p<0.05)$ and INTER muscles $(r=-0.78, p<0.05)$ deoxygenation response.

Conclusion: This interim analysis reveals that in COPD patients, high-intensity TFRL induces greater mechanical and physiological stimulus to inspiratory muscles compared to $\mathrm{NH}$. 